\title{
ECONOMIA DE PAPEL EM ESCRITÓRIOS DE CONTABILIDADE
}

\author{
Anderson dos SANTOS ${ }^{1}$ \\ Indiele SALES ${ }^{2}$ \\ Maurício Cézar Rezende LEITE JÚNIOR ${ }^{3}$ \\ Talilian Joelma BORGES ${ }^{4}$ \\ Alexandre Tourino MENDONÇA ${ }^{5}$
}

\begin{abstract}
${ }^{1}$ Graduando em Ciências Contábeis da Universidade Vale do Rio Verde (UninCor), anderson-santos-02@ hotmail.com. ${ }^{2}$ Graduando em Ciências Contábeis da Universidade Vale do Rio Verde (UninCor), indycia@ hotmail.com.

${ }^{3}$ Professor Tempo integral na Universidade Vale do Rio Verde (UninCor), Doutor em Recursos Hídricos em Sistemas Agrícolas, mauricio_cezar_leite@yahoo.com.br.

${ }^{4}$ Professora na Universidade Vale do Rio Verde (UninCor), talilianborges@ yahoo.com.br.

${ }^{5}$ Professor Tempo integral na Universidade Vale do Rio Verde (UninCor), Doutor em Ciências dos Alimentos. pesquisa@unincor.edu.br.
\end{abstract}

Recebido em: 08/06/2016 - Aprovado em: 09/01/2017 - Disponibilizado em: 01/07/2017

\begin{abstract}
RESUMO:
Os desafios dos dias contemporâneos é fazer com que as forças do mercado e as pessoas adquiram uma consciência ecológica e melhorem a qualidade do ambiente. Nestes novos tempos, os clientes começaram a mudar suas posturas e esperam que as empresas, escritórios e lojas sejam mais éticos ambientalmente, através de uma produção ou serviços mais "limpos", transparentes e com ações voltadas para o desenvolvimento sustentável. Com o crescimento da importância da questão ambiental, as organizações têm realizado melhorias ambientais, estimuladas por órgãos de controle ambiental e pela mídia, que, por sua vez reflete a vontade e interesse do publico em geral, em busca de uma melhor qualidade de vida. Por vezes, essas melhorias são conseguidas a forças de lei, regulamentos e fiscalizações pelos órgãos ambientais. Percebe-se que todos os escritórios, empresas, lojas e qualquer outros lugares, não podem mais desconsiderar os aspectos relacionados a preservação do meio ambiente, e a variável "conscientização ambiental", tem se tornado um importante diferencial competitivo com o qual as empresas e comercio devem se preocupar. No contexto do escritório de contabilidade, percebe-se um excessivo consumo de papeis diariamente. O processo de fabricação de celulose, de onde vem o papel, é altamente poluente, tanto que as fabricas de celuloses devem ficar afastada dos centros urbanos. Economizar papel significa utilizar menos recursos naturais, sendo assim identificar como é consumido o papel em escritórios de contabilidade irá agregar na contribuição do consumo de papel ecologicamente correto.
\end{abstract}

Palavra Chave: Desafio, questão ambiental, consumo.

\section{PAPER SAVER IN ACCOUNTING OFFICES}

\begin{abstract}
:
The challenges of contemporary days is to make market forces and people to acquire ecological awareness and improve the quality of the environment. In these new times, customers began to change their positions and expect companies, offices and shops are more environmentally ethical, through a production or services "cleaner", transparent and actions for sustainable development. With the growing importance of environmental issues, organizations have made environmental improvements stimulated by environmental organizations and the media, which in turn reflects the will and interest of the general public, in search of a better quality of life. Sometimes, these improvements are achieved the law forces, regulations and inspections by environmental agencies. It is noticed that all offices, businesses, shops and any other places, can not ignore the aspects related to environmental conservation, and the variable "environmental awareness", has become an important competitive advantage with which businesses and trade should be concerned. In the accounting office of the context, it is perceived excessive consumption of paper daily. The pulp manufacturing process, hence the paper, is highly polluting, so that the factories of pulps should stay away from urban centers. Save paper means using fewer natural resources, therefore identify how consumed the paper accounting office will add the contribution of environmentally friendly paper consumption.
\end{abstract}

Keyword: Challenge, environmental issues, consumption. 


\section{INTRODUÇÃO}

Os desafios dos dias contemporâneos é fazer com que as forças do mercado e as pessoas adquiram uma consciência ecológica e melhorem a qualidade do ambiente. Nestes novos tempos, os clientes começaram a mudar suas posturas e esperam que as empresas, escritórios e lojas sejam mais éticos ambientalmente, através de uma produção ou serviços mais "limpos", transparentes e com ações voltadas para o desenvolvimento sustentável.

O desenvolvimento tecnológico deve ser orientado para metas de equilíbrio com a natureza e de incremento de capacidade de inovação dos países em desenvolvimento; o progresso deve significar a integração de maior riqueza, maior benefício social equitativo e equilíbrio ecológico. Para este tipo de desenvolvimento ser compatível com o equilíbrio ecológico, situações irreversíveis como a destruição da biodiversidade ou o esgotamento de certas matérias-primas devem ser evitadas, os gastos com papel são um dos principais motivos de desmatamento no mundo. $\mathrm{O}$ fato é que esse material é essencial no dia-a-dia de grande parte da população, mas há maneiras de evitar seu desperdício (BARBIERI, 2005).

A preservação do meio ambiente converteu-se em um dos fatores de maior influencia dos anos 90 e da primeira década de XX, com grande rapidez de penetração de mercado. Assim, as empresas, comércios e escritórios começam a apresentar soluções para alcançar o desenvolvimento sustentável e, ao mesmo tempo, aumentam a lucratividade de seus negócios. Uma forma de aproveitar ao máximo a matéria e evitar gastos desnecessários, já que a fabricação do produto exige uma grande quantidade de água e energia.

Com o crescimento da importância da questão ambiental, as organizações têm realizado melhorias ambientais, estimuladas por órgãos de controle ambiental e pela mídia, que, por sua vez reflete a vontade e interesse do publico em geral, em busca de uma melhor qualidade de vida. Por vezes, essas melhorias são conseguidas a forças de lei, regulamentos e fiscalizações pelos órgãos ambientais (FIORILLO. 2008).

Percebe-se que todos os escritórios, empresas, lojas e qualquer outros lugares, não podem mais desconsiderar os aspectos relacionados a preservação do meio ambiente, e a variável "conscientização ambiental", tem se tornado um importante diferencial competitivo com o qual as empresas e comercio devem se preocupar (SEIFFERT,2007).

Com isso, o objetivo geral desse artigo é identificar de que forma é consumido o papel em escritório de contabilidade, visando contribuir com o consumo ecologicamente correto, tendo como objetivos específicos, identificar em quais processos os funcionários de um escritório de contabilidade gasta mais 
papel, avaliar a percepção dos colaboradores quanto a necessidade das impressões realizadas e propor ações que resultem em economia de papel.

\section{METODOLOGIA}

Foi elaborado um questionário com perguntas fechadas, com o intuito de que fossem levantadas as principais questões que envolvem essa pesquisa, tais como a quantidade de impressões realizadas pelos funcionários dos escritórios de contabilidade e a finalidade dessas impressões.

Esse questionário foi enviado a quatro escritórios de contabilidade e as perguntas referentes a gasto de papéis foram elaboradas de acordo com o período que não envolvesse a entrega obrigatória do imposto de renda, pois nesses dias, os escritórios ficam assoberbados e o que predomina é a competência para que o prazo de validade da entrega da declaração do imposto de renda não seja vencido. Sendo assim, o gasto de papel é quase o dobro nesse período de acordo com os escritórios.

Segue abaixo as perguntas do questionário enviado aos escritórios de contabilidade:

Os escritórios receberam este questionário entre os dias 09 e 11 de março e recebemos estes questionários entre os dias 25 e 27 do mesmo mês.

Abaixo estão listados os escritórios que receberam este e-mail e quantos funcionários responderam este questionário em cada um dos escritórios:

1. Escritório 01: CIC - Contabilidade Geral. Endereço: Av. Presidente Getulio Vargas, 318, Três Corações MG. 06 funcionários que responderam o questionário.

2. Escritório 02: INCOLA - Organização Contábil. Endereço: Rua Rui Barbosa, 57, Três corações - MG. 06 funcionários que responderam $\mathrm{o}$ questionário.

3. Escritório 03: Escritório Inova.Endereço: Praça Liberdade, 50, centro, Jesuania - MG.04 funcionários que responderam $\mathrm{o}$ questionário.

4. Escritório 04: Escritório Lambari. Endereço: Rua Wenceslau Braz, 178, Lambari - MG. 03 funcionários que responderam o questionário.

\section{RESULTADOS E DISCUSSÃO}

Percebe-se de modo geral que as organizações não podem desconsiderar os aspectos relacionados á preservação do meio ambiente, e a variável ambiental vêm se tornando o mais importante diferencial competitivo com o qual as empresas devem se preocupar (BREMBATTI, 2013).

A empresa que não perceber isso poderá vir a perder uma falta considerável de mercado consumidor, as organizações terão 
que se modernizar se adequar ás necessidades do mercado e começar a considerar a questão ambiental com uma vantagem competitiva (SILVA, 2004).

Sendo assim, uma das perguntas do questionário era se os funcionários do escritório de contabilidade havia conhecimento da quantidade de papel que são impressos:

No total de 04 escritórios, são 19 funcionários, sendo que $10,6 \%$ desses funcionários responderam que acham um consumo excessivo de papel, mais que na correria do dia, acabam aderindo à impressão e 89,4\% funcionários disseram não fazer à mínima ideia da quantidade de papel impressa. (Figura 1).

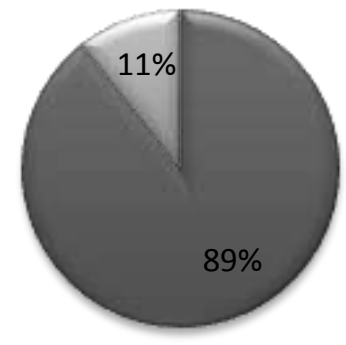

$89,40 \% \square 10,60 \%$

Figura 1: Conhecimento de documentos impresso.

Fonte: Os autores.

O outro levantamento feito, gira em torno dos documentos que são impressos, dessa forma nota-se que muitos dos documentos impressos são temporários, ou seja, são documentos que não são necessários imprimir, pois poderiam ficar armazenados no próprio computador. $\mathrm{Na}$ Tabela 1, podem-se analisar essas informações.

Tabela 1: Tipos de documentos impressos e quantidade

\begin{tabular}{lll}
\hline \multicolumn{1}{c}{ Documentos } & Quantidade diária impressa & $\begin{array}{l}\text { Percepção dos funcionários } \\
\text { quanto a não impressão dos } \\
\text { documentos. }\end{array}$ \\
\hline $\begin{array}{l}\text { Relatórios de demonstrações } \\
\text { contábeis }\end{array}$ & $+/-20$ impressões & $\begin{array}{l}\text { Diminuição total já que esses } \\
\text { relatórios podem ser enviados } \\
\text { por e-mail. }\end{array}$ \\
\hline Informações da internet & $+/-05$ impressões & $\begin{array}{l}\text { Diminuição total já que essas } \\
\text { informações poderiam ser salvas } \\
\text { no computador. }\end{array}$ \\
\hline $\begin{array}{l}\text { Cadastro ou informações de } \\
\text { cliente }\end{array}$ & $\begin{array}{l}\text { Diminuição quase que total já } \\
\text { que as informações dos clientes } \\
\text { poderiam ser sanadas pelo e- } \\
\text { mail. }\end{array}$ \\
\hline Notas fiscais & $+/-15$ impressões & $\begin{array}{l}\text { Difícil diminuir, pois as notas } \\
\text { fiscais são de mera importância } \\
\text { nos escritórios de contabilidade. }\end{array}$ \\
\hline
\end{tabular}

Fonte: Os autores.

Importante ressaltar que os dados acima são apenas de um escritório de contabilidade, e que também existem outros documentos e relatórios que são impressos, mais os que foram descritos acima foram os mais citados. 
Observa-se então nas informações acima que são em torno de 80 impressões diárias e que os próprios funcionários que responderam o questionário colocaram meios de diminuição de impressões, que com isso resultam uma economia de quase metade de impressões diárias. Um dos resultados que trouxe informações relevantes foi a respeito da percepção do funcionário em relação ao numero elevado de impressão, no que aproximadamente $85 \%$ dos funcionários acreditam que existe uma elevada quantidade de impressões. (figura 2).

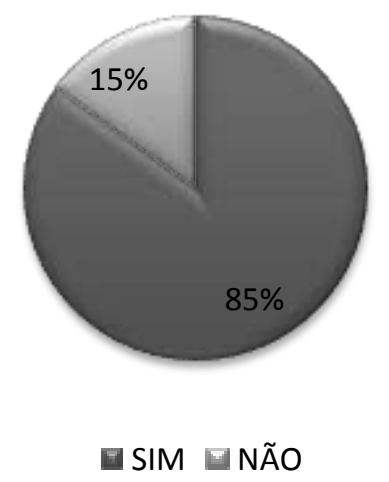

Figura 2: Existe um número excessivo de impressões?

Fonte: Os autores.

O motivo do número excessivo de impressões foi devido ao hábito de imprimir que se tornou automático, a impressão de documentos desnecessários e a impressão de documentos que muitas vezes são lidos e jogados fora. Dos funcionários que responderam que nem todas as impressões realizadas são necessárias, esses destacaram que imprimem muitos documentos desnecessários, porém alguns mesmo que ainda podendo ser salvos no computador, existe uma obrigatoriedade de serem impressos.

Para o começo de uma mudança comportamental em relação à impressão nos escritórios de contabilidade, se coloca uma pergunta dizendo: $\mathrm{O}$ que você vai imprimir é realmente necessário?

Visando os dados anteriores a resposta não é tão difícil de achar, sendo assim, é automático o pensamento de mudança de conduta, ações e métodos de diminuir as impressões já estão inseridas nas próprias respostas acima, o que falta é uma consciência ambiental, e isto se dá através de ações rotineiras.

Segundo Dias (2013) é necessária uma economia de papel no instituto mediante pesquisa que ela realizou usando questionário enviado para a secretaria e sala de Xerox. Com base no questionário dele (Dias, 2013), levantaram-se os seguintes dados:

a) É necessária uma conscientização geral dos usuários das impressoras; existindo, por exemplo, a possibilidade de impressão no verso da folha economizando papel;

b) Investimento em papéis reciclados para anotações e até mesmo impressões; 
c) Uma conscientização dos alunos ao solicitar o Xerox que pode ser impresso as apostilas ou qualquer outro documento usando a frente e o verso das folhas.

Confrontando as informações do trabalho de Dias (2013) com o trabalho que esta sendo realizado, é visível que a palavra chave para ambos os trabalhos é uma conscientização maior e melhor para qualquer usuário do papel, sua economia acarreta menores impactos no meio ambiente $\mathrm{e}$ considerável economia monetária com compras de papel.

Foi elaborada uma lista com meios de como economizar papel usando a pesquisa de Dias (2013) e a pesquisa realizada neste trabalho:

a) Evitar impressões desnecessárias, revisando o arquivo na tela do computador antes de imprimir;

b) Utilizar mais e-mails;

c) Usar o método de digitalização para evitar impressões;

d) Adotar sistemas eu facilitem a economia de papel ao imprimir documentos, tais como usar o papel frente e verso;

Assim, se reafirma a importância em qualquer setor sobre a economia de papel, considerando tudo o que foi falado $\mathrm{e}$ pesquisado, dizendo que economizar papel requer uma conscientização de todos os usuários.

Segundo a CEMPRE (2005), para a sociedade, os benefícios de um meio ambiente mais saudável geram melhores condições de vida, principalmente em relação à saúde, a educação, buscando desenvolver a consciência ética e valores morais, e uma nova formação de exercício de cidadania, coletividade, organização e limpeza urbana, geração de renda e emprego por meio de iniciativas voltadas para a coleta seletiva do lixo e a reciclagem.

A importância deste trabalho para os escritórios de contabilidade pode possuir medidas imensuráveis, visto que a cada dia pode-se perceber a degradação ambiental que traz prejuízos ainda não muito pensados pelo homem, sendo de imensa amplitude a conscientização de todos quantos á racionalização dos recursos naturais.

De acordo com CAIXETA; MARTINS (2008), a melhor maneira de reduzir a quantidade de resíduos sólidos é combatendo o problema na origem, ou seja, através da redução na fonte, isto pode ser feito através da substituição de matérias-primas ou da mudança na tecnologia dos processos.

A sociedade precisa compreender a necessidade de reduzir e reciclar seus resíduos, pois dessa maneira se diminui a utilização de matérias-primas virgens, que em alguns casos começarão a apresentar uma situação de escassez. 
A administração de uma organização tem responsabilidade pessoal em conservar e proteger o meio ambiente para as futuras gerações. Esse sentimento de responsabilidade e dedicação pessoal é a melhor razão para reduzir o impacto ambiental da organização no meio ambiente, pois isso irá se refletir em melhores resultados em longo prazo.

\section{CONCLUSÃO}

Percebeu-se que muitos documentos são impressos pelos funcionários, tais como relatórios, informações da internet e notas fiscais.

O consumo de papel nesses escritórios foi calculado por volta de 80 impressões diárias por escritório, sendo essa pesquisa feita fora do período de entrega das declarações de imposto de renda, pois o consumo de papel nesses períodos são maiores.

Os funcionários percebem que existe um elevado numero de impressões, e apontam que a maioria dos documentos é desnecessária de serem impressos e alguns que tem necessidade de impressão podem ser revisados antes de serem impressos de forma errada o que teria que acarretar outra impressão.

\section{REFERÊNCIAS}

BARBIERI, J. C. Desenvolvimento e meio ambiente: as estratégias de mudanças da Agenda. 7 ed. ver. E atual. Petrópolis, RJ: Vozes, 2005.

BREMBATTI, katia Brembatti. Empresas reduzem o uso de papel: consciência ambiental. Gazeta do povo. 2012

CAIXETA, S.V; MARTINS, RS. Gestão de logística de transportes de cargas. São Paulo: Atlas, 2008.

CEMPRE - COMPROMISSO EMPRESARIAL PARA RECICLAGEM. Reduzindo, reutilizando, reciclando: a indústria da eco eficiência. São Paulo: SENAI, 2005.

COSTA FILHO, Adalberto Vieria et.al. Responsabilidade social nas empresas. São Paulo: Peirópolis, 2005.

DIAS 2013, Taís Silveira Dias; aluna do curso de Tecnologia em Gestão Ambiental do IFMG. Diagnóstico do consumo de papel A4 no Instituto Federal de Minas Gerais. 2013

FIORILLO, Celso Antônio Pacheco. Curso de direito ambiental brasileiro. 5. ed. São Paulo: Saraiva, 2008.

SEIFFERT, Mari Elizabete Bernardini. Instrumentos, Esferas de Ação e Educação Ambiental. São Paulo: Atlas, 2007.

SILVA, José Afonso da. Direito Constitucional Ambiental. 2. ed. São Paulo: Malheiros, 2004. 